In the chief meizoseismal zone the shock was preceded by a very loud rumbling like the firing of a gun, and the perceptible movement, which occurred in three separate phases, was estimated to last about thirty seconds. The time of the shock within this area is known with considerable accuracy, the clock at the geodynamic observatory of Messina having stopped at $5 \mathrm{~h}$. $2 \mathrm{rm}$. 30s., or 4h. $2 \mathrm{Im}$. 3os. Greenwich mean time. On the Calabrian shores, the sea-waves were greatest at Pellaro, Lazzaro, and Gallico; in Sicily, near Briga, Riposto and Paradiso; they were distinctly perceptible at Malta, and were registered by the tide-gauges at Porto d'Ischia, Naples, Civitavecchia, Porto Corsini, and even in the neighbourhood of Venice.

Dr. Baratta attributes the disastrous results of the recent earthquake chiefly to three causes-the damage resulting from preceding earthquakes, and especially those of 1894, 1905, and 1907; the nature of the rocks on which the houses were built; and the wretched materials used and a system of construction in complete contradiction to the elementary rules that should govern all building in seismic countries. He gives the following scale of foundations, beginning with the worst:- yellow sands, sands and conglomerates in irregular beds, recent alluvia, Miocene sands and conglomerates, limestones and crystalline rocks. The recent earthquake he regards as far inferior in intensity to the first great shock of 1783 , which produced permanent changes in the ground and attained a maximum mortality, though occurring in the daytime, of 77 per cent. at Terranova.

\section{PHTHISIS AND INSANITY IN RELATION TO INHERITANCE.}

A MEMOIR "On the Inheritance of the Diathesis of Phthisis and Insanity," by Dr. Charles Goring, has been issued by Messrs. Dulau and Co. in the series of Drapers' Company Research Memoirs, emanating from the Department of Applied Mathematics, University College, London. The methods used are similar to those employed by Prof. Pearson in his "First Study of the Statistics of Pulmonary Tuberculosis" and by Mr. Heron in his "First Study of the Statistics of Insanity," but the data are better in one respect, inasmuch as they are based, not on hospital or asylum cases, but upon information obtained respecting the inmates of convict prisons. Whether; however, such a sample can be correctly described as a random sample of the general population, as the author holds, is certainly open to question.

The conclusions reached by Dr. Goring are confirmatory of those previously put forward by Pearson and by Heron: for both phthisis and insanity he finds a very marked correlation between parents and offspring, the coefficients fluctuating round 0.5 . In the case of phthisis no evidence is found of infection between husband and wife, the marital correlation being insignificant and negative. When, however, the author states, arguing against the view that the observed correlation between parent and child may be due to infection, that "upon statistical evidence one conclusion alone seems to follow inevitably and may be asserted without reserve. It is that such parental infection, if existent, is relatively inconsiderable, and that almost the whole of the parental association in phthisis represents an inherited predisposition in the child to be infected with the disease of his parents : that the one vital factor in the occurrence of tuberculosis is inheritance," he makes in the last sentence an assertion which it is a little difficult to excuse. To mention only the best known data, he will find in part ii. of each of the last two decennial supplements published by the RegistrarGeneral ample evidence that the mortality from phthisis is five to ten times as great for persons engaged in certain occupations as for persons engaged in others; it is surely idle, with such evidence at hand, to argue that environmental factors are of no importance!

We do not wish to underrate the value of the memoirthe author deserves the thanks of all those interested in the problem for his reduction and discussion of the databut we think it should be read with caution, as the writer appears insufficiently acquainted with the other evidence NO. 2094, VOL. 82] bearing on the question. In conclusion, a doubt may be raised whether the most satisfactory method of studying the influence of heredity on phthisis is to deal as a whole with a random sample of the general population. In view of the widely divergent liabilities of different occupations to phthisis, the heterogeneity of the sample may very well unduly increase the correlations observed.

SOME PAPERS ON AMERICAN ZOOLOGY.

THE mammal and bird fauna of Alaska and Yukon territory forms the subject of No, 30 of the "North American Fauna" (U.S. Department of Agriculture). The author, Mr. W. H. Osgood, gives the results of his observations, both on the nature of the country and the fauna, made during three traverses, namely, one through east central Alaska, a second through the Ogilvie Range of the Yukon, and a third along the course of the Macmillan River. The habits, mutual relationships, and range of the different species form the main subject of the biological section, new names being very few. The attention of sportsmen may be directed to certain observations connected with the habits of moose; but, so far as mammals are concerned, the chief interest in this issue is concentrated in the announcement that the pure white bighorn sheep of the Kenai Peninsula, the so-called Ovis dalli, passes by imperceptible gradations into the black sheep (O. stonei) of the Stikine Valley. For the future these northern wild sheep must be regarded as local races of the Rocky Mountain Bighorn.

Nos. $x 701$ and $x 702$ of the Proceedings of the U.S. National Museum are devoted to the description of portions of the collections obtained during the cruise of the Albatross in rgo6. In the first of these Miss H. Richardson gives an account of the isopod crustaceans collected in the north-west Pacific. In addition to the new Holotelson-a member of the eubranchiate section distinguished by the emargination of the terminal segment of the abdomen-the author describes a very large number of new species, especially in the genus Arcturus.

Fresh-water sponges from the Philippines form the subject of the second paper (No. I702). The collection was submitted to Dr. Annandale, of the Indian Museum, who refers some of the specimens to Spongilla philippinensis, a species described by himself earlier in the present year, and the rest to a new species, $S$. microsclerifera.

In No. 1703 of the same publication Mr. J. P. Moore describes a collection of polychætous annelids dredged last year off the coasts of Labrador, Newfoundland, and Nova Scotia. Most of the specimens came from Labrador, and all are referred to species already known. They serve to confirm the supposition that the Labrador polychætes would prove to belong mainly to Arctic types, with some admixture from a more southern fauna.

\section{STEAM TURBINES. ${ }^{1}$}

I $N$ the first lecture it was pointed out that the first practical steam engine was Newcomen's, about the middle of the eighteenth century, and it used about $20 \mathrm{lb}$. of coal per horse-power hour. James Watt succeeded in reducing this to $5 \mathrm{lb}$. or $7 \mathrm{lb}$. of coal per horse-power hour, chiefly through the introduction of the separate condenser, and the Watt engine remained in principle without other than detail improvements until the gradual rise of steam pressure, and consequent extra expansion, caused compound, triple, and finally quadruple expansion engines to be introduced, and as a result the coal bill is now some one-fifteenth of what it was in the time of Newcomen.

It has, however, been found that with reciprocating engines there must be a steam pressure of about $7 \mathrm{lb}$. per square inch on the low-pressure piston, or otherwise its size and weight become excessive, and also that there is little or no benefit in going to a higher vacuum than about $25^{\prime \prime}$

With the steam turbine, vacua of $28 \frac{1}{2} "$ or $29^{\prime \prime}$, or absolute pressures of from $\frac{3}{4} 1 \mathrm{~b}$. to $\frac{1}{2} \mathrm{ib}$. per square inch, can be easily utilised, since the difficulty of dealing with large

I Abstract of three Cantor lectures delivered before the Royal Society of Arts by Mr. Gerald Stoney, and published in the Journal of the Society for October 8,15 , and 22 
volumes of steam does not occur in the case of the steam turbine as in the case of the reciprocating engine, and it has been found that with the steam turbine the gain due to vacuum goes steadily on up to the highest attainable vacua. Between $25^{\prime \prime}$ and $26^{\prime \prime}$, or $26^{\prime \prime}$ and $27^{\prime \prime}$, there is a gain of about 4 per cent.; a further gain of 5 per cent. is made with the vacuum increased to $28^{\prime \prime}$, and a still further gain of 6 per cent. to 7 per cent. when it is increased to $29^{\prime \prime}$.

This is more easily understood if we consider that the theoretical power to be derived from the steam is almost proportional to the logarithm of the expansions, and thus practically the same power can be obtained working from $400 \mathrm{lb}$. to I $\mathrm{lb}$. absolute, or $28^{\prime \prime}$ vacuum, as from $200 \mathrm{lb}$. to $\frac{1}{2} \mathrm{lb}$., or $29^{\prime \prime}$ vacuum. In each case there are 400 expansions by pressure, and in each case the theoretical consumption of steam by Clausius' cycle would be about $9.3 \mathrm{lb}$. per kilowatt hour. With $150^{\circ} \mathrm{F}$. superheat this would come down to $8.7 \mathrm{lb}$, and under the conditions of $200 \mathrm{lb}$. pressure and $29^{\prime \prime}$ vacuum with $150^{\circ} \mathrm{F}$. superheat, I3.2 lb. per kilowatt hour has actually been obtained with an overall efficiency, including the alternator, of about 66 per cent., or $71 \frac{1}{2}$ per cent. on the turbine shaft, allowing for the electrical losses. Prof. Ewing, in his book on "The Steam Engine," gives a list of principal results obtained from condensing reciprocating engines, and in no case does the ratio of the consumption of steam by Clausius' cycle, compared with that used per indicated horse-power, exceed 64 per cent. As the ratio of brake horse-power to indicated horse-power is never more than 90 per cent., this means an efficiency at the engine shaft of not more than $5^{8}$ per cent. When it is remembered that the figure obtained in the case of the turbine was $71 \frac{1}{3}$ per cent., and further that the reciprocating engine is unable to take advantage of high vacua, it is easily seen where the advantage of the turbine, especially in large sizes, comes in.

The other advantages were dealt with of absence of vibration, reduced cost of repairs and maintenance, and space occupied, this last being only in some cases one-third or one-fourth of that necessary for reciprocating engines.

In very large sizes, also, it has been found practically impossible to make reciprocating engines satisfactory, and it may not, perhaps, be generally known that one of the reasons which led the Cunard committee to adopt turbines for the great express steamers Lusitania and Mauretania was the fact that the engineering difficulties of the enormous reciprocating engines required made the problem almost impossible of solution without the use of turbines.

Steam turbines may be divided into two great divisions, single and compound. In the former class there is the De Laval, in which the whole of the expansion is carried out in a single jet, but in order to get efficiency the speed of revolution is so high that gearing has to be resorted to, and this limits this type of turbine to small sizes.

The second class is that universally adopted for all large turbines, in which the expansion of the steam is carried out in stages.

The compound turbine naturally divides itself into two subclasses, those in which the expansion of the steam takes place both in the fixed and moving blades, and those in which it takes place in the fixed blades only. Included in the former class is the Parsons, while the latter contains the Rateau, Zoelly, Curtis, and various others. In the Rateau and Zoelly, which strongly resemble one another, the velocity of the steam at each stage is taken up by a single row of blades mounted on a wheel, and in the Curtis by a wheel having two or more rows of moving blades with guide blades between. There are also various combinations of these, especially those with a Curtis highpressure part and a Parsons low-pressure, but as yet they have not come largely into use.

A description is then given of the various types of turbine, and also the method of calculating the blading and other particulars, along with some practical rules for their design, and it is shown that, with these limitations, turbines can be constructed with similar stresses and dimensions to give outputs varying as the square of their dimensions and inversely as the square of the speed of revolution.

Now it can be shown that alternators also obey the same iule of varying inversely as the square of the speed, and NO. 2094, VOL. 827 thus it will be seen that alternators coupled to turbines go up in size together, and that, apart from the trouble there is due to being compelled to have an even number of poles, alternators of the maximum size for that speed have similar turbines attached to them, and thus there is no limit to the size of turbo-alternator. In the case, however, of continuous current dynamos, the output of a dynamo (as it is chiefly limited by commutation conditions which depend principally on the ampere turns on the armature per inch diameter) is practically only proportional to the speed, and it is easily seen that a limit is soon reached where the speed of the turbine is too low for economical conditions.

However, by using tandem dvnamos it will be seen that the output is doubled, and this enables tandem turbodynamos up to about 4000 kilowatts to be economically built

In the second lecture various applications of and auxiliaries to the steam turbine were described.

The design of condensers has been especially influenced by the introduction of steam turbines. As has been shown, in the old days of reciprocating engines, the condenser giving $25^{\prime \prime}$ vacuum was quite good enough, but nowadays, on account of the great improvement in economy of steam turbines, with higher vacua, it is common to have between $28^{\prime \prime}$ and $29^{\prime \prime}$.

The maximum vacuum which can be obtained from a condenser is the vacuum due to the temperature of the outlet water, and the closer to this we can get the vacuum actually obtained the better. There are two ways of expressing this difference: one is by pressure and the other is by temperature, and for condenser work the latter is the more convenient. When it is remembered that from about $24^{\prime \prime}$ to $27^{\prime \prime}$. each inch of vacuum makes 4 per cent. difference in the steam consumption of a turbine, between $27^{\prime \prime}$ and $28^{\prime \prime}$ about 5 per cent., and from $28^{\prime \prime}$ to $29^{\prime \prime} 6$ per cent. or 7 per cent., or that, approximately, $3^{\circ} \mathrm{F}$. difference in the temperature of the exhaust means an increase or decrease of about $r$ per cent. in steam consumption, it is easily understood how important it is to keep the difference of temperature between the outlet water from the condenser and the temperature due to the vacuum as small as possible. This difference in good modern condensers, when condensing, say, I2 lb. per square foot per hour, can be kept as low as $5^{\circ} \mathrm{F}$. or $6^{\circ} \mathrm{F}$.

Another way of looking at the efficiency of the condenser is the B.T.U. transmitted per square foot of cooling surface per hour per $I^{\circ} \mathrm{F}$. difference of temperature, and this figure can in well-constructed condensers be as high as I000 to I200 B.T.U.

It is in connection with the extracting of air thoroughly from the condenser that the greatest improvements have been made of late years, and amongst these dry air pumps and the vacuum augmentor are especially prominent. This latter consists simply of a jet of steam drawing the air and vapour from the condenser and delivering it through a small auxiliary condenser to the air pump, and thus, although the air pump may only produce a vacuum of, say, $27^{\prime \prime}$ or $28^{\prime \prime}$, there may be a vacuum of $28^{\prime \prime}$ to $29^{\prime \prime}$ in the condenser, and in practice this appliance has been found most satisfactory. The effect of using this vacuum augmentor has been in some cases to bring up the conductivity from about 250 or 300 to between 800 and 1000 , or to reduce the loss of temperature from some $26^{\circ} \mathrm{F}$. to $5^{\circ}$ F., a gain in temperature of, say, $21^{\circ}$ F., or 7 per cent., in the consumption of the turbine.

When it is remembered that the steam jet of the vacuum augmentor only uses about 0.6 per cent. of the steam used by the turbine, it is easily seen that the gain cue to the better vacuum is vastly more than the loss due to the steam jet.

One great field for turbines which has only within the last couple of years come into prominence, although it was patented by Mr. Parsons some years ago, is the use of exhaust turbines, that is, turbines taking steam at atmospheric pressure from reciprocating engines or other machinery, and utilising the power contained in it in an exhaust turbine. When it is remembered that there is as much power in steam working from atmospheric pressure down to a $27^{\prime \prime}$ vacuum as between $150 \mathrm{lb}$. down to atmospheric pressure, it is easily seen that the power of an 
existing non-condensing plant can be more than doubled by the simple application of an exhaust steam turbine and condenser. Such installations are now in use all over the country, and from being absolutely a waste product exhaust steam has become a most valuable by-product in many works. In many cases the exhaust. steam is intermittent, such as the exhaust steam from a winding engine of a colliery. Such intervals, if not too long, can be bridged over by a thermal accumulator. The principle of thermal storage is itself a comparatively old idea in connection with steam boilers, having been proposed by Druitt Halpin in $\mathrm{I} 8 \mathrm{~g} \mathrm{I}-2$, but the best-known form of accumulator for use in connection with exhaust steam turbines is that of Prof. Rateau, where a tank containing water has the exhaust steam blown through it so that alternately the exhaust steam is partly condensed, and the water in the tank boils, and thus the supply given to the turbine is constant.

In many cases, however, the stops are too long to be bridged over by any form of thermal accumulator, and in such cases what are called " mixed pressure" turbines have been introduced, in which there is a high-pressure part revolving idly when exhaust steam is used, but when the exhaust steam supply fails, by an automatic arrangement this high-pressure part is supplied with live steam, and thus the turbine continues to be driven.

The first applications of the stcam turbine to driving machinery were in the driving of electrical machinery, and on land this still continues to be the greatest use for steam turbines, and a full account of turbo-alternators and dynamos is given.

An important development during the past few years has been the application of the steam turbine for driving air compressors. An ordinary steam turbine when driven backwards does not act as an air compressor, but if the blades are suitably shaped it forms a very efficient one, and this fact has led to a large development in the application of steam turbines.

Such turbo-blowing engines are largely used for blast furnaces, the blast pressures required ranging generally from ro $\mathrm{lb}$. to $16 \mathrm{lb}$. per square inch.

It may be mentioned that the weight of a turbo-blowing engine complete is 25 tons, and the weight of a reciprocating engine of the same power 430 tons, or seventeen times heavier than the turbine.

For producing pressures higher than $25 \mathrm{lb}$. per square inch, the design of the blowing engine is usually of the centrifugal type, and consists of a number of centrifugal fans specially constructed to withstand the stresses caused by the high speed of revolution.

In the third lecture an account is given of the greatest development of the steam turbine, that for marine propulsion.

The large and increasing amount of horse-power, and the greater size and speed of the modern engines, tend towards some form which shall be light, capable of perfect balancing, and economical in steam. The marine engine of the piston type does not fulfil these requirements. This led to the well-known Turbinia being built, which proved the success of the steam turbine for marine propulsion. After the Turbinia, the Viper and Cobra, torpedo-boat destroyers, followed, but the next great step was the King Edward, built in 1902 . The arrangement of the turbines was altered considerably from that of the Turbinia in order to get increased manœuvring power. Three shafts were still retained, with two screws on the wing shafts and one on the centre shaft, which revolved at rather lower speed; but, instead of all the three turbines being in series, the steam passed first through the centre high-pressure one, and then was divided between two low-pressure turbines, port and starboard. In the same casing as these lowpressure turbines, and at the exhaust end, the stern turbines were incorporated. This gave much better manouvring power than with the arrangement in the Turbinia, as when manceuvring the high-pressure turbine was cut out and steam admitted direct to either or both of the low-pressure turbines or to the astern turbines, thus giving as good mancuvring power as in the case of a twin-screw ship with reciprocating engines.

The success of the King Edward, together with that of the Viper and Cobra, led the Admiralty to have turbines fitted into one of four third-class cruisers, and the vessel NO. 2094, VOL. 82] chosen was the Amethyst. Extensive trials were carried out between her and her sister ship, the Topaz, with reciprocating engines, each heing $35^{\circ}$ feet long and of 3000 tons displacement. The result was that at all speeds above I4 knots the turbine was the more economical, being I5 per cent. better at I 8 knots, $3 \mathrm{I}$ per cent. better at $20 \frac{1}{2}$ knots, and 38 per cent. better at $22 \cdot \mathrm{r}$ knots.

With cross-Channel boats it has been found that the turbine vessels use 25 per cent. less coal per passenger, and travel 2 knots faster, than those with reciprocating engines, and the Lusitania has been shown by Sir William White to be 16 per cent. more efficient than the great German reciprocating liners.

The application of the steam turbine to the propulsion of slow-speed ships, that is, ships of below 15 to 18 knots, has up to the present been difficult, owing to the low speed of revolution of the screws making the turbines large and heavy, as well as not economical. This difficulty has now been got over by the use of an arrangement patented by Mr. Parsons sone years ago, viz. the combination of reciprocating engines and exhaust turbines, similar to what was described before for land work. Here each utilises the part of the expansion for which it is best suited - the reciprocating engine for the high-pressure part of the range and the turbine for the low-pressure where the volume of steam is large.

It is interesting to note that in the early days of the screw propeller the great difficulty was to make the engines run fast enough for the screw, and spur gearing was adopted in many cases in the first half of the last century. Gearing has been entirely dropped for the last fifty or sixty vears, but now the difficulty in many cases is to make the turbine run slow enough for the screw, and once more gearing is being considered so as to make the turbine adaptable for use in slow-speed steamers, which, after all, constitute by far the greater part of the shipping of the world.

The combination system described above does this, but gearing a high-speed turbine to a slow-speed screw would also accomplish what is needed.

Eighty years ago there was nothing but primitive spur gearing, with generally wooden teeth in one member, but now we have steel gears accurately cut by modern machinery, often with helical teeth, and running in oil baths.

At the present date there are about izo vessels actually on service fitted with turbines, representing about $\mathrm{r}, 250,000$ horse-power, and these comprise practically all the highspeed ships which have been recently built. Some seventy more are under construction, representing another $1,000,000$ horse-power, or a total of $2,250,0$ o horse-power, and the curve of progress as yet shows no sign of saturation.

\section{THE OUTLOOK OF SCIENCE.}

PROBABLY there never was a time when the scientific spirit was more active than at the present moment. We see evidence of this on all hands. In the realms of abstract science we have researches dealing with profound questions as to the intimate nature of matter that were not within the sphere of thought only a few years ago. The theories of electrons which are founded on mathematical and physical investigation give us a glimpse into worlds of movement of which those before us had no conception, and of stores of energy that may one day be liberated in the service of mankind. That mysterious agency, electricity, is now seen to be probably at the basis of all phenomena, physical, chemical, vital, and a new interpretation is given of many actions going on all around us. The relation of matter to the circumambient xther also engages the speculations of men of science.

Researches at extremely low temperatures, down near to absolute zero, as carried out by Dewar, are enabling the physicist and chemist to criticise the properties of matter from a new point of view. The microscope, hitherto an instrument used mostly by the biologist, is now employed in the investigation of the molecular structure of metals and other substances, as these are modified

1 From an address delivered to the ascociates and students of the flasgow McKend ick, F.R.S. 